\title{
Evolution of the Rust Layers Formed on Carbon and Weathering Steels in Environment Containing Chloride Ions
}

\author{
Xin-Liang Gao ${ }^{1} \cdot$ Yi Han ${ }^{1} \cdot$ Gui-Qin $\mathrm{Fu}^{2} \cdot$ Miao-Yong $\mathrm{Zhu}^{2} \cdot$ Xing-Zhong Zhang ${ }^{1}$
}

Received: 11 May 2016/Revised: 22 June 2016/Published online: 22 August 2016

(C) The Chinese Society for Metals and Springer-Verlag Berlin Heidelberg 2016

\begin{abstract}
To clarify the correlation between alloy elements and growth pattern of the rust layers, the rusting evolution of the carbon and weathering steels was investigated by using the gold markers method. The corrosion experiments were carried out in a simulated environment containing chloride ions. The results indicate that $\mathrm{Ni}, \mathrm{Cu}, \mathrm{Cr}$ and $\mathrm{Mo}$ elements in the weathering steel suppress the rust crystallization and impede the rust layer growth to an internal development, and the suppression function benefits the formation of a protective rust layer. Moreover, $\gamma-\mathrm{FeOOH}$ is mainly located in the outer rust layer, while $\beta-\mathrm{FeOOH}$ is mainly located in the inner rust layer, and the distribution of the rust compounds in the rust layer is closely related to the growth pattern of the rust layer.
\end{abstract}

KEY WORDS: Atmospheric corrosion; Steel; Rust layer; SEM; Chloride ions

\section{Introduction}

Atmospheric corrosion of the steel is an interaction between the steel and its surrounding atmospheric environment [1-3]. As a corrosion product, the composition and structure of the rust layer have a remarkable effect on the corrosion rate of the steel $[4,5]$. Since the marine atmosphere contains abundant chloride ions [6-8], the rust layer formed under the marine atmosphere is different from that formed in the rural or industrial atmosphere. The rust formed in the marine atmosphere is mainly composed of $\alpha-\mathrm{FeOOH}$ (goethite), $\gamma$-FeOOH (lepidocrocite), $\quad \beta$-FeOOH (aka-

Available online at http://link.springer.com/journal/40195

Xin-Liang Gao

yejingxl@163.com

$1 \quad$ National Engineering Research Center for Equipment and Technology of Cold Strip Rolling, Yanshan University, Qinhuangdao 066004, China

2 School of Metallurgy, Northeastern University, Shenyang 110819, China ganeite), $\mathrm{Fe}_{3} \mathrm{O}_{4}$ (magnetite) and amorphous compounds, and the physical and chemical properties of those components are significantly different [9-17]. In order to study the effect of the composition of the rust layer on corrosion behavior, the protective ability index (PAI) has been applied to evaluate the effect since Yamashita et al. [18] and Kamimura et al. [10] and Hara et al. [11] found the correlation between PAI and corrosion rate. The corrosion resistance of the steel is not only affected by the composition of the rust layer, but also by its structure [19, 20], so some investigators, for example Yamashita et al. [18], Ma et al. [7, 21], Monnier et al. [22] and Zhang et al. [23], paid a lot of attention to the structure of the rust layer. They believed that the distribution of different components in the rust layer had a remarkable effect on the structure of the rust layer.

A small addition of the alloy elements such as $\mathrm{Ni}, \mathrm{Cu}$, $\mathrm{Cr}$ and Mo can effectively improve the physical and chemical properties of the rust layer. For example, Ni substitutes for $\mathrm{Fe}$ ions in the oxide, forming a spinel oxide, and meanwhile raising the proportion of nanophasic or superparamagnetic goethite in the inner rust layer, which then favorably forms a compact rust 
layer [24, 25]. The cation-selective property of the rust layer appears under the marine atmosphere when the content of $\mathrm{Ni}$ in steel is more than $3 \mathrm{wt} \%[26,27] . \mathrm{Cu}$ in the rust layer suppresses the nucleation and growth of $\alpha$ $\mathrm{FeOOH}$ and $\gamma-\mathrm{FeOOH}$, which can facilitate the formation of a compact rust layer [28, 29]. Cr partially substitutes for $\mathrm{Fe}$ ions in iron oxyhydroxide to form $\alpha-\mathrm{Cr}_{x} \mathrm{Fe}_{1-x} \mathrm{OOH}$ and then changes the rust structure suppressing the anion permeability due to its cation-selective property, which favorably forms a protective rust layer [30, 31]. Mo with $\mathrm{MoO}_{4}{ }^{2-}$ state accumulated in the inner rust layer facilitates the formation of a compact rust layer, which slows down the corrosion rate of the steel substrate [32, 33]. Due to the improvement of the physical and chemical properties of the rust layer, the corrosion resistance of the weathering steel is much higher than that of the carbon steel [34].

Although the correlation between the components and structure of the rust layer has been studied by many investigators, the studies on the effect of growth pattern on the structure of the rust layer have rarely been reported. Therefore, Burger et al. [35] studied the atmospheric corrosion behavior of iron by using a gold marker method and found that the growth pattern affects the structure of the rust layer. The gold markers method consists of (1) sputtering a non-continuous film of gold on the original surface of the samples, (2) corroding marked samples in a simulated environment and (3) analyzing the corrosion patterns on cross section by scanning electron microscopy (SEM) and the other testing equipments. If the non-continuous gold thin layer is distributed within the rust layer, the proportion of inner/outer rust layers will thus enable to estimate the proportion of inward and outward mechanisms [35]. Since the weathering steel usually contains a small amount of alloy elements, the growth pattern of the rust layer formed on the weathering steel may be different from that of the iron. Furthermore, in the corrosion process, the different structures of the rust layers formed on the weathering steel and the carbon steel may be caused by the different growth patterns. However, there are few reports on the relationship between the alloy elements and the growth patterns of rust layers. As a result, the present work aims to study the difference between the growth patterns of the rust layers formed on the carbon steel and the weathering steel in an environment containing chloride ions. Based on the evolution of corrosion in a simulated environment, the correlation between alloy elements and growth patterns of the rust layers is discussed using the analysis techniques, such as gold marker method, corrosion weight loss, and so on.

\section{Experimental}

\subsection{Preparation of Samples}

The carbon steel and the weathering steel (see Table 1) were cut to a small size $(30 \mathrm{~mm} \times 20 \mathrm{~mm} \times 5 \mathrm{~mm})$ and then ground by 4000 grit silicon carbide papers. Afterward, the samples were cleaned with acetone, distilled water and alcohol, respectively. After drying, each of the samples was weighed as $W_{0}(\mathrm{~g})$. One surface of some of the samples was coated with a thin gold layer, which is by sputtering a gold cathode for $180 \mathrm{~s}$ under $\arg$ on $(5 \mathrm{~Pa})$ with a current of $21.5 \mathrm{~mA}$ and an anode/cathode distance of $70 \mathrm{~mm} \mathrm{[35].}$ The samples coated with a thin gold layer would be used to investigate the effect of the growth pattern of the rust layers on the structure.

\subsection{Wet/Dry Cyclic Corrosion Test}

The corrosion behavior of the experimental steels was simulated in the environment containing chloride ions by an alternate wet/dry corrosion test. During each cycle, the samples were immersed into $0.1 \mathrm{~mol} \mathrm{~L}^{-1} \mathrm{NaCl}$ solution for $18 \mathrm{~min}$ at $42{ }^{\circ} \mathrm{C}$ and then dried for $62 \mathrm{~min}$ at $45^{\circ} \mathrm{C}$ with a $(32 \pm 2) \%$ relative humidity $(\mathrm{RH})$. After the experimental period of time $(48,96,144,240$ and $336 \mathrm{~h}$ ), the samples were taken out for analysis. Each sample was weighed as $W_{1}$ (g) after drying for $24 \mathrm{~h}$ at the ambient temperature. In order to analyze the corrosion weight loss of the samples after different corrosion times, the rust was removed by an ultrasonic cleaner with a solution of $500 \mathrm{~mL}$ hydrochloric acid $+500 \mathrm{~mL}$ distilled water $+20 \mathrm{~g}$ hexamine. Subsequently, the samples were rinsed with anhydrous alcohol, dried in air and weighed as $W_{2}(\mathrm{~g})$. The corrosion weight gain, the rust weight and corrosion weight loss of the samples can be calculated by the following equations:

$m_{\mathrm{g}}=\frac{W_{1}-W_{0}}{S}$

$m_{\mathrm{r}}=\frac{W_{1}-W_{2}}{S}$,

$m_{\mathrm{c}}=\frac{W_{0}-W_{2}}{S}$

where $m_{\mathrm{g}}\left(\mathrm{g} \mathrm{cm}^{-2}\right)$ is the corrosion weight gain per unit area, $m_{\mathrm{r}}\left(\mathrm{g} \mathrm{cm}^{-2}\right)$ is the rust weight per unit area, $m_{\mathrm{c}}$ $\left(\mathrm{g} \mathrm{cm}^{-2}\right)$ is the corrosion weight loss per unit area, $S\left(\mathrm{~cm}^{2}\right)$ is the surface area of the sample.

The corrosion rate of the sample was determined by the following equation [21]:

$v_{\mathrm{c}}=\frac{m_{n}-m_{n-1}}{t_{n}-t_{n-1}}$ 
Table 1 Chemical composition of experimental steels (mass\%)

\begin{tabular}{llllllllll}
\hline Sample & $\mathrm{C}$ & $\mathrm{Si}$ & $\mathrm{Mn}$ & $\mathrm{P}$ & $\mathrm{S}$ & $\mathrm{Ni}$ & $\mathrm{Mo}$ & $\mathrm{Cr}$ & $\mathrm{Cu}$ \\
\hline Carbon steel & 0.15 & 0.25 & 0.72 & 0.02 & $<0.01$ & - & - & - \\
Weathering steel & 0.08 & 0.20 & 1.06 & 0.02 & $<0.01$ & 0.28 & 0.18 & 0.50 & 0.29 \\
\hline
\end{tabular}

where $v_{\mathrm{c}}\left(\mathrm{g} \mathrm{cm}^{-2} \mathrm{~h}^{-1}\right)$ is the corrosion rate, $m_{n}\left(\mathrm{~g} \mathrm{~cm}^{-2}\right)$ is the corrosion weight loss of the samples corrupted for $t_{n}$. When $n=1,2,3,4,5$, it means that the samples were corrupted for 48, 96, 144, 240 and 336 h, respectively.

\subsection{Rust Analysis}

The rust powder was scraped from the rusted sample surface by a razor blade for X-ray diffraction (XRD) analysis. $\mathrm{Cu}$ target was used, and the scanning speed was set as $2^{\circ} \min ^{-1}$ with a $2 \theta$ angle range of $10^{\circ}-55^{\circ} . \mathrm{ZnO}$ was used as an internal standard, and the ratio of $\mathrm{ZnO}$ to corrosion products was 3:7 $[9,10]$. Crystalline rust phases were $\boldsymbol{\alpha}$ $\mathrm{FeOOH}, \gamma-\mathrm{FeOOH}, \beta-\mathrm{FeOOH}$ and $\mathrm{Fe}_{3} \mathrm{O}_{4}$. The diffraction intensities of the $\left(\begin{array}{lll}0 & 1 & 1\end{array}\right)$ reflection of $\alpha-\mathrm{FeOOH}$, the $\left(\begin{array}{lll}0 & 2 & 0\end{array}\right)$ reflection of $\gamma-\mathrm{FeOOH}$, the (1 110$)$ reflection of $\beta-\mathrm{FeOOH}$ and the (2 20 ) reflection of $\mathrm{Fe}_{3} \mathrm{O}_{4}$ were measured and compared with the $\left(\begin{array}{lll}1 & 0 & 0\end{array}\right)$ reflection of $\mathrm{ZnO}$ powder $[9,36]$.

A scanning electron microscope (SEM) was applied to study the surface and cross-sectional morphology of the rust layers, and electron microprobe analysis (EMPA) was also used to analyze the alloy elemental distribution in the rust layers. Besides, a Raman spectroscope (JY-HR 800) equipped with a He-Ne laser of $633 \mathrm{~nm}$ was employed to investigate the characteristics of the rust compounds at different locations in the rust layers. The power of the laser was kept at $1.7 \mathrm{~mW}$ to avoid the transformation of the rusts due to the heating effect of the laser. A magnification of 500 times was employed when focusing on the specimens.

Polarization measurements were carried out with an Autolab electrochemical workstation. The rusted sample with an exposed area of $1 \mathrm{~cm}^{2}$ was used as a working electrode, while a saturated calomel electrode (SCE) and a large of area platinum were served as reference electrode and counter electrode, respectively. The polarization curves were obtained with a constant scan rate of $2 \mathrm{mV} \mathrm{s}^{-1}$ at room temperature $\left[(25 \pm 1){ }^{\circ} \mathrm{C}\right]$, and the electrolyte was $0.1 \mathrm{~mol} \mathrm{~L}^{-1} \mathrm{NaCl}$ aqueous solution.

\section{Results}

\subsection{Corrosion Kinetics}

Figure 1a illustrates the evolution of the corrosion weight loss with time in the simulated environment containing chloride ions. It shows that the corrosion weight loss of the two experimental steels increase gradually as the corrosion proceeds. Moreover, the corrosion weight loss of the carbon steel is significantly higher than that of the weathering steel, and this trend becomes evident with increasing test time. The relationship between the corrosion rate and the time is shown in Fig. 1b. It can be seen that during the corrosion procedure, the corrosion rate of carbon steel firstly increases, then decreases and finally increases again, while the corrosion rate of the weathering steel firstly increases and then decreases. The phenomena shown in Fig. 1b indicate that the corrosion mechanism of the samples varies in the corrosion procedure. Moreover, the corrosion rate of the carbon steel increases from 144 to $336 \mathrm{~h}$, indicating that the rust layer formed on the carbon steel surface is not corrosion-protective, while the corrosion rate of the weathering steel decreases at the same corrosion time, which means that the protective rust layer is formed on the weathering steel.

Since the rust layers attached to the steels have a significant influence on the corrosion behavior of the steels, the rust weight per unit area, which approximately characterizes the thickness of the rust layers, was calculated by Eq. (2), and the results are shown in Fig. 1c. Clearly, the rust weight per unit area increases gradually as the corrosion time prolongs, which is consistent with the trend of the corrosion weight loss of the steels. Both the rust weight per unit area and the corrosion rate of the carbon steel are larger than those of the weathering steel, indicating that there is not evident correlation between the protective property of the rust layers and their thickness.

\subsection{XRD of Rust Layers}

Figure 2 shows the rust phase constitution studied by XRD. As shown in Fig. 2, $\alpha-\mathrm{FeOOH}, \gamma-\mathrm{FeOOH}, \beta-\mathrm{FeOOH}$ and $\mathrm{Fe}_{3} \mathrm{O}_{4}$ are detected. In order to analyze the effect of alloy elements on the corrosion products in the rust layers, a quantitative determination is carried out as shown in Fig. 3. The X-ray amorphous compounds are mainly microcrystalline oxides or hydroxides and cannot be identified by XRD. By comparing the rust phases after 144-h corrosion, it can be seen that the content of amorphous compounds of the weathering steel is higher than that of the carbon steel, while the contents of $\alpha-\mathrm{FeOOH}, \gamma-\mathrm{FeOOH}, \beta-\mathrm{FeOOH}$ and $\mathrm{Fe}_{3} \mathrm{O}_{4}$ of the weathering steel are lower than those of the 
(a)

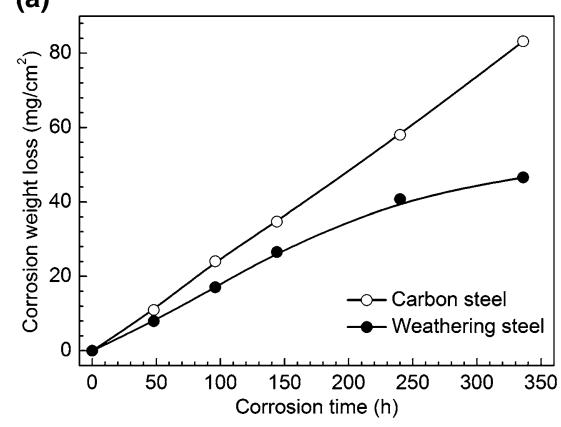

(b)

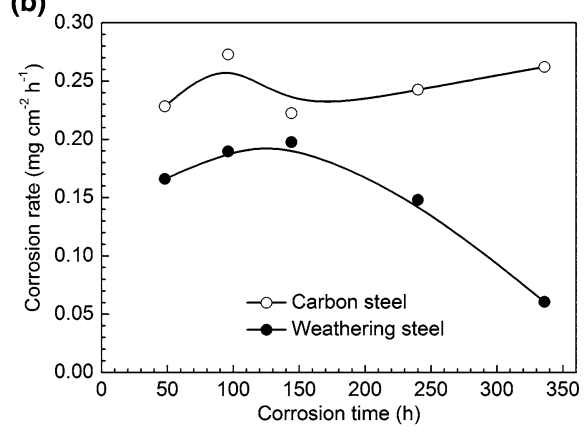

(c)

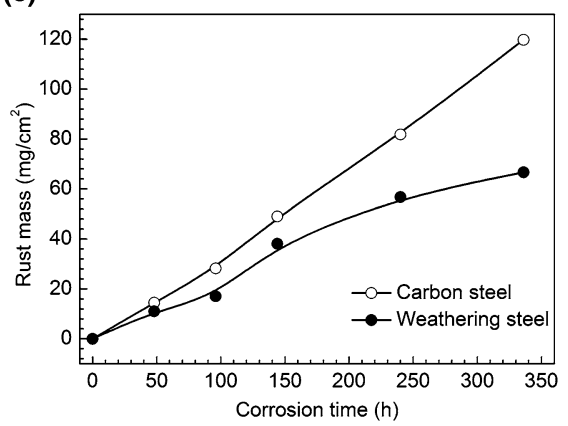

Fig. 1 Corrosion weight loss a, corrosion rate b, rust mass $\mathbf{c}$ versus time for the two experimental steels
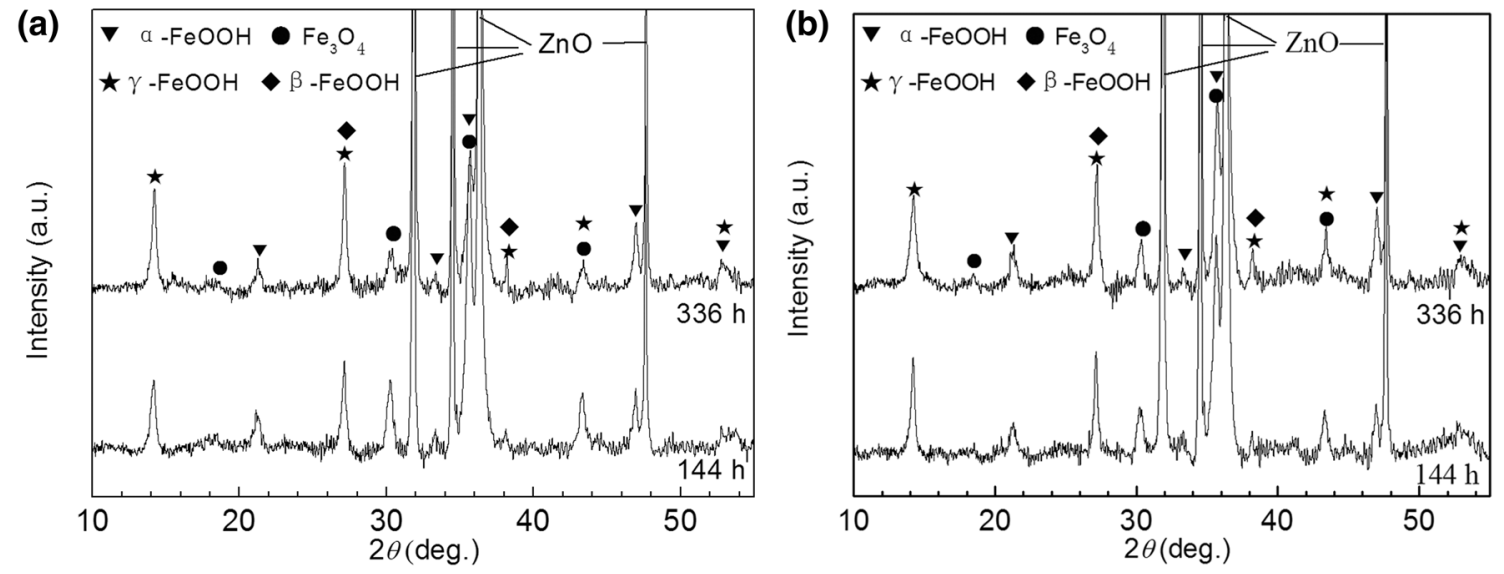

Fig. 2 XRD patterns of the rust layers formed on the carbon a and weathering $\mathbf{b}$ steels surfaces after different corrosion times

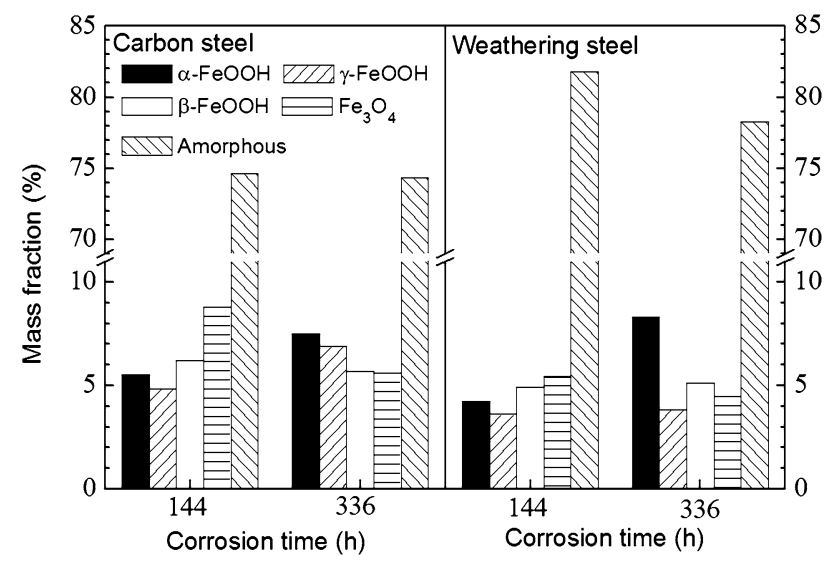

Fig. 3 Quantitative analysis of different phases of the rust layers formed on the experimental steel surfaces after different corrosion times

carbon steel. After 336-h corrosion, the contents of the amorphous compounds and $\alpha-\mathrm{FeOOH}$ of the weathering steel are higher than those of the carbon steel, while the contents of $\gamma-\mathrm{FeOOH}, \beta-\mathrm{FeOOH}$ and $\mathrm{Fe}_{3} \mathrm{O}_{4}$ are lower than those of the carbon steel. Therefore, it can be seen that the alloy elements $(\mathrm{Ni}, \mathrm{Cr}$, Mo and $\mathrm{Cu})$ suppress the formation of crystal phases.

\subsection{Localization of Gold Markers in the Rust Layers}

In order to investigate the effect of the growth pattern of the rust layers on their structures, the gold marker method was used. Before the application of this method, it is necessary to confirm that the gold markers exist in the rust layers, and they will not affect the corrosion kinetics and growth pattern of the rust layers. The Au element distribution shown in the elemental mapping confirms the existence of the gold marker with discontinuous agglomerations and also shows that its thickness is approximately $0.4-0.6 \mu \mathrm{m}$. The comparison between the corrosion weight gains with and without gold markers proves that the gold markers have little effect on the corrosion kinetics (as shown in Fig. 4). Moreover, after the different corrosion times (144, 240 and $336 \mathrm{~h}$ ), comparative observations between the gold-coated and the blank samples confirm that the existence of the gold markers affects neither the structure nor the growth nature of the rust layers (see Figs. 5c, d, 6c, d).

Figure 5 illustrates the cross-sectional morphologies of the rust layers formed on the weathering steel after different corrosion times. During the test period, the gold 


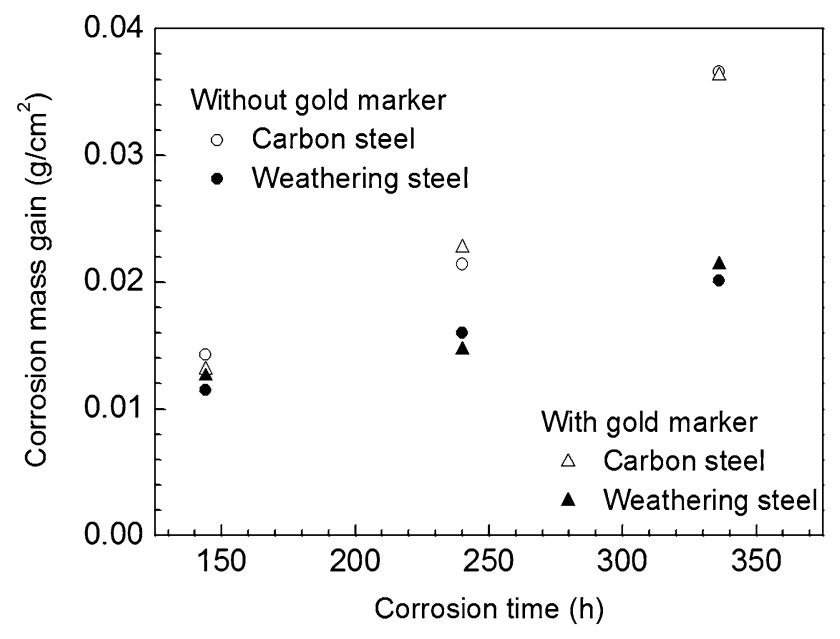

Fig. 4 Corrosion weight gain of the samples with and without gold markers after different corrosion times

markers are always located within the rust layer, and the inner rust layer (the proportion of the rust layer from the gold marker to the steel substrate) is thicker and more compact than the outer rust layer (the proportion of the rust layer from the gold marker to the external surface of the rusted sample). The outer rust layer is formed by dissolution of the corrosion products in solution, and subsequent precipitation and deposition on the external surface of the rust layer, while the formation of inner rust layers is believed as the corrosion products precipitated in the steel substrate [35]. As described above, the difference in growth patterns of the inner and outer rust layers may explain the difference of their morphologies. In addition, the thickness of the internal rust layer increases with test time. As shown in Fig. 6, the evolution of the cross-sectional morphologies of the rust layers and the variation of the gold markers in the rust layers on the carbon steel have a similar trend with those on the weathering steel. However, the inner rust layer of the carbon steel seems to have more flaws such as cracks and pores than that of the weathering steel, indicating that the alloy elements $(\mathrm{Ni}, \mathrm{Cu}, \mathrm{Cr}$ and $\mathrm{Mo})$ affect the structure of the rust layers.

In order to analyze the location variation of the gold markers within the rust layers, a quantitative method was used to measure the thickness of the outer and inner rust layers. The rust layer was divided into successive
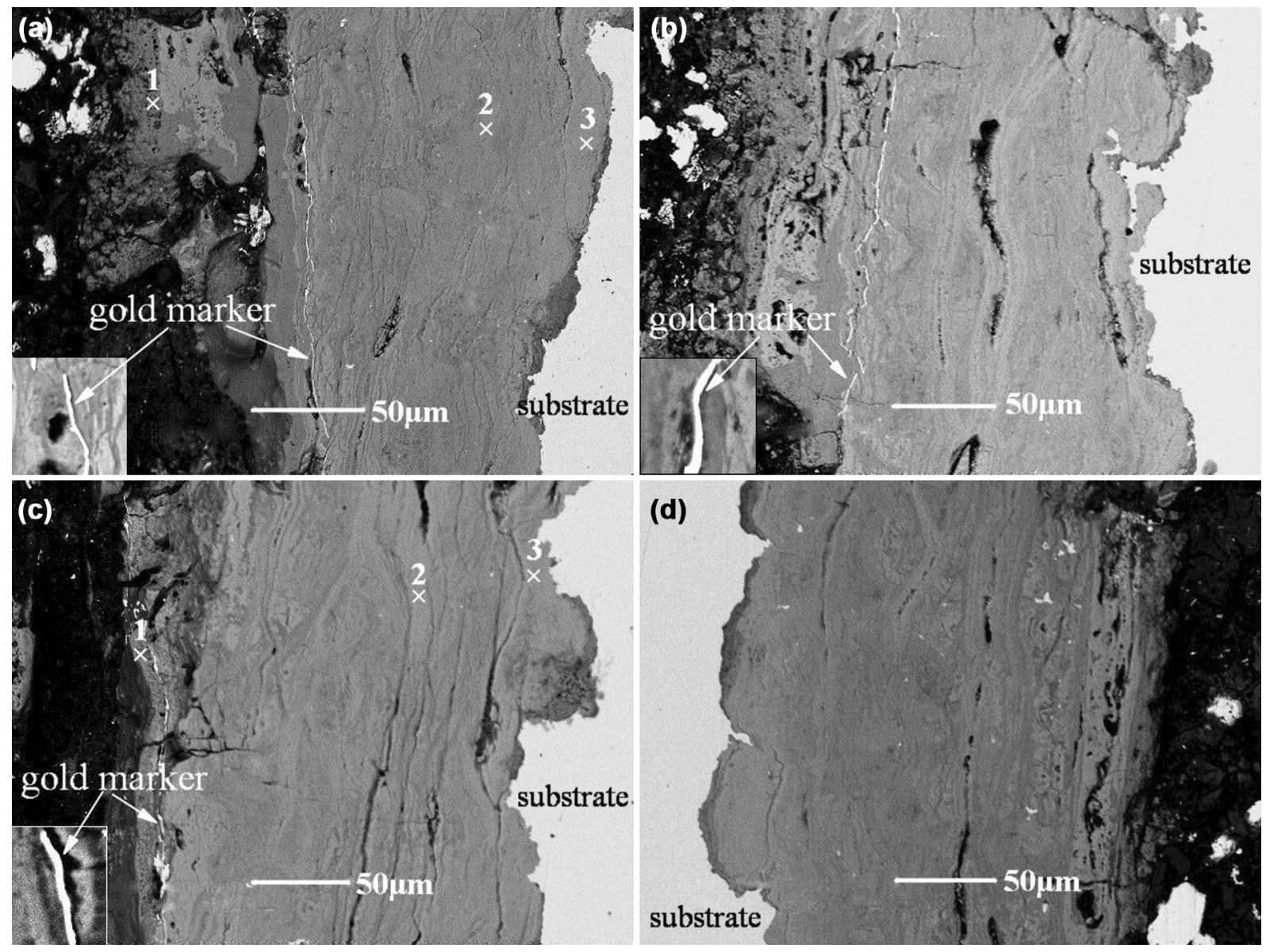

Fig. 5 Morphologies of the rust layers with gold markers of the weathering steel corrupted for $144 \mathrm{~h} \mathrm{a}, 240 \mathrm{~h} \mathrm{~b}, 336 \mathrm{~h}$ c, without gold markers corrupted for $336 \mathrm{~h} \mathrm{~d}$ 

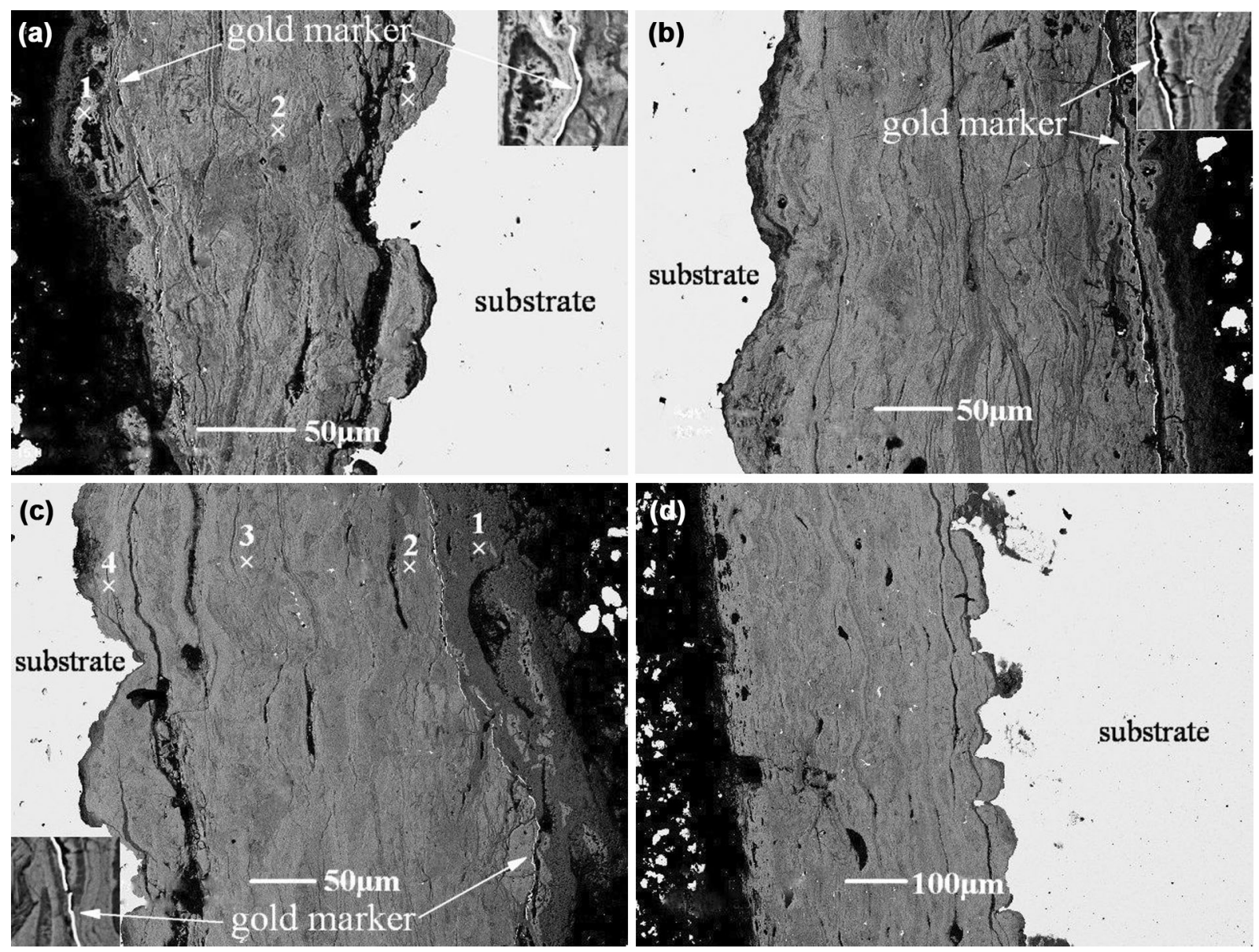

Fig. 6 Morphologies of the rust layers with gold markers of the carbon steel corrupted for $144 \mathrm{~h} \mathrm{a}, 240 \mathrm{~h} \mathrm{~b}, 336 \mathrm{~h}$ c, without gold markers corrupted for $336 \mathrm{~h} \mathrm{~d}$

equidistant rectangular zones (length $400 \mu \mathrm{m}$ ) along the whole length of the samples $(\sim 3 \mathrm{~cm})$, and the thickness of the rust layers was measured. The average of the thickness is shown in Fig. 7. It is clear that the inner rust layer is thicker than the outer part. Meanwhile, the thickness of the inner rust layers formed on the weathering steel is less than that on the carbon steel, which indicates that the alloy elements $(\mathrm{Ni}, \mathrm{Cu}, \mathrm{Cr}$ and $\mathrm{Mo})$ hinder the internal development of rust layers.

As seen from the rust surface morphologies of the carbon and the weathering steels shown in Fig. 8, there is a significant difference in the structure of the outer and inner rust layers after 336-h corrosion. It is observed that the morphologies of the outer rust surface show the characteristic feature of $\gamma-\mathrm{FeOOH}$, which consists of flowery and acicular crystals, and $\alpha-\mathrm{FeOOH}$, which shows cotton-ball-type structures (as shown in Fig. 8a, b) [6, 7]. Furthermore, the outer rust layers have a porous nature. In contrast, the inner rust layers of the experimental steels are fine and compact, which can effectively restrain the penetration of corrosive solution. Meanwhile, there is an obvious difference in the

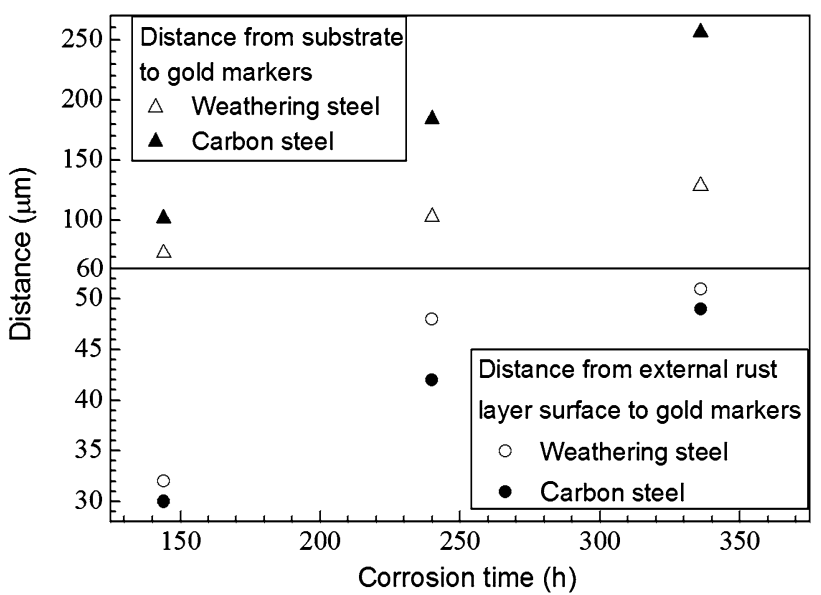

Fig. 7 Quantification of positions of gold markers in rust layers after different corrosion times

morphologies of the inner rust layers formed on the carbon and the weathering steels, but little difference in those of the outer rust layers, and the phenomena confirm that the alloy elements affect the structures of the inner rust layers. 

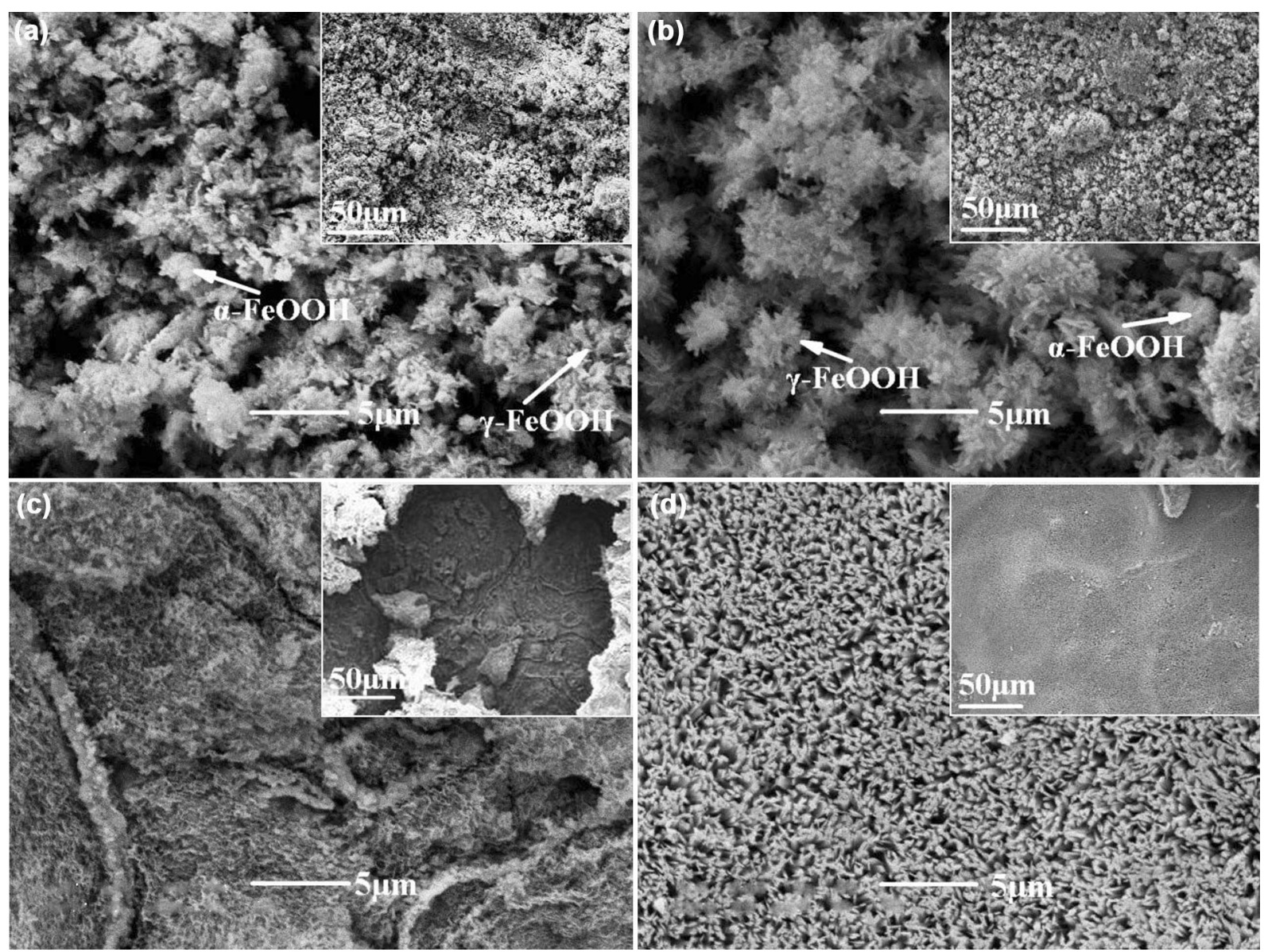

Fig. 8 Morphologies of the outer rust surface on the carbon $\mathbf{a}$ and weathering $\mathbf{b}$ steels without gold markers, and inner rust morphologies of the carbon $\mathbf{c}$, the weathering d steels without gold markers corrupted for $336 \mathrm{~h}$

\subsection{Raman Characterizations of Rust Compounds}

In order to analyze the compositions of the different locations in the rust layers, a Raman spectroscopy was used. For the carbon steel corrupted for $144 \mathrm{~h}$, spectra on a mixture of the different oxides and hydroxides were recorded as shown in Figs. 6a, 9a. The oxides and hydroxides of iron were identified by the literature values [37]. The corrosion products of Point 1 located in the outer rust layer are mainly composed of $\gamma-\mathrm{FeOOH}, \alpha-\mathrm{FeOOH}$ and $\mathrm{Fe}_{3} \mathrm{O}_{4}$, while the corrosion products of Points 2 and 3 located in the inner rust layer are mainly composed of $\beta$ $\mathrm{FeOOH}, \alpha-\mathrm{FeOOH}$ and $\mathrm{Fe}_{3} \mathrm{O}_{4}$. In addition, the characteristic peak intensities of the oxides and hydroxides decrease from the external rust layer surface to the internal rust layer, indicating that the extent of rust crystallization decreases. For carbon steel, after 336-h corrosion as shown in Figs. 6c, 9b, the corrosion products of Point 1 located in the outer rust layer are mainly composed of $\gamma-\mathrm{FeOOH}, \alpha-$ $\mathrm{FeOOH}$ and $\mathrm{Fe}_{3} \mathrm{O}_{4}$, while the corrosion products of Points
3 and 4 located in the inner rust layer are mainly composed of $\beta-\mathrm{FeOOH}, \alpha-\mathrm{FeOOH}$ and $\mathrm{Fe}_{3} \mathrm{O}_{4}$. However, the corrosion products of Point 2 located in the inner rust layer consist of $\alpha-\mathrm{FeOOH}$ and $\mathrm{Fe}_{3} \mathrm{O}_{4}$, while $\beta-\mathrm{FeOOH}$ is not detected, which may be because that $\beta-\mathrm{FeOOH}$ is gradually transformed into $\alpha$-FeOOH or $\mathrm{Fe}_{3} \mathrm{O}_{4}$ during wet-dry cyclic corrosion, since $\beta-\mathrm{FeOOH}$ is highly active [15]. Figures 5a and $9 \mathrm{c}$ show the compositions of the different locations in the rust layer formed on the weathering steel after 144-h corrosion. The corrosion products of Point 1 located in the outer rust layer are mainly composed of $\gamma-\mathrm{FeOOH}, \alpha$ $\mathrm{FeOOH}$ and $\mathrm{Fe}_{3} \mathrm{O}_{4}$, while the corrosion products of Points 2 and 3 located in the inner rust layer are mainly composed of $\beta-\mathrm{FeOOH}, \alpha-\mathrm{FeOOH}$ and $\mathrm{Fe}_{3} \mathrm{O}_{4}$. Meanwhile, a similar composition distribution in the rust layer formed on the weathering steel corrupted for $336 \mathrm{~h}$ is shown in Figs. 5c, $9 \mathrm{~d}$, but $\beta-\mathrm{FeOOH}$ is not detected in Point 2 , which is a similar reason with that of the carbon steel corrupted for $336 \mathrm{~h}$. As described above, it can be seen that $\gamma-\mathrm{FeOOH}$ is mainly located in the outer rust layer, and $\alpha-\mathrm{FeOOH}$ and 

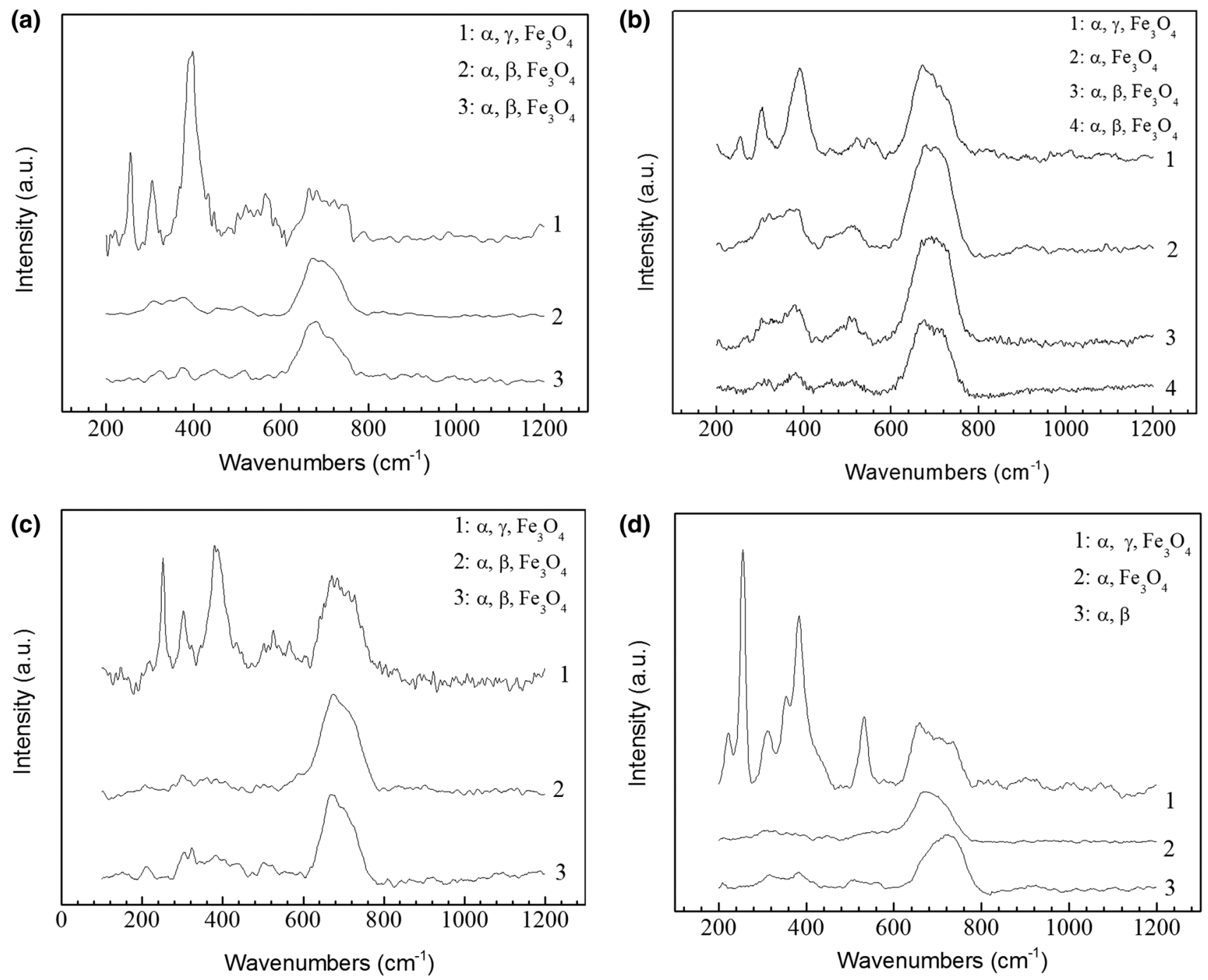

Fig. 9 Raman spectroscopy in different locations of rust layers with gold markers of the carbon steel $\mathbf{a}, \mathbf{b}$ and weathering steel $\mathbf{c}, \mathbf{d}$ corrupted for $144 \mathrm{~h}$ a, c, $336 \mathrm{~h} \mathrm{~b}, \mathbf{d}$

$\mathrm{Fe}_{3} \mathrm{O}_{4}$ are located in both the outer and inner rust layers, while $\beta-\mathrm{FeOOH}$ is only located in the inner rust layer.

\subsection{Distribution of Alloy Elements in the Rust Layers}

Figure 10 shows the distribution of $\mathrm{Ni}, \mathrm{Cr}, \mathrm{Mo}$ and $\mathrm{Cu}$ elements in the rust layer with and without the gold markers studied by EMPA. Clearly, $\mathrm{Cr}$, $\mathrm{Mo}$ and $\mathrm{Cu}$ are enriched in the inner rust layer, while $\mathrm{Ni}$ is uniformly distributed in the whole rust layer. The distribution of alloy elements in the rust layer without gold markers is similar to that with gold markers, indicating that the gold markers have little effect on the distribution of alloy elements in the rust layer. The distribution of the alloy elements in the rust layer influences the structure and growth pattern of the rust layers, which will be analyzed in Sect. 4 .

\subsection{Polarization Measurements}

Figure 11 shows the polarization curves of the rusted weathering steel samples corrupted for different time in $0.1 \mathrm{~mol} \mathrm{~L}^{-1} \mathrm{NaCl}$ solution. The cathodic process of the rusted samples is mainly controlled by reduction of the rust due to the presence of the active compounds (such as $\gamma$ - $\mathrm{FeOOH}$ and $\beta-\mathrm{FeOOH}$ ) in the rust layers, while the anodic process is controlled by steel dissolution. With prolonging corrosion time, the corrosion potential moves to the positive, and the anodic and the cathodic processes are inhibited, which indicates that the protective property of the rust layers is enhanced. The level of difficulty of the cathodic reaction is due to the compact extent and active compound content of the rust layers, while the level of difficulty of the anodic reaction is mainly due to the active anodic area, but the content of the active compounds 

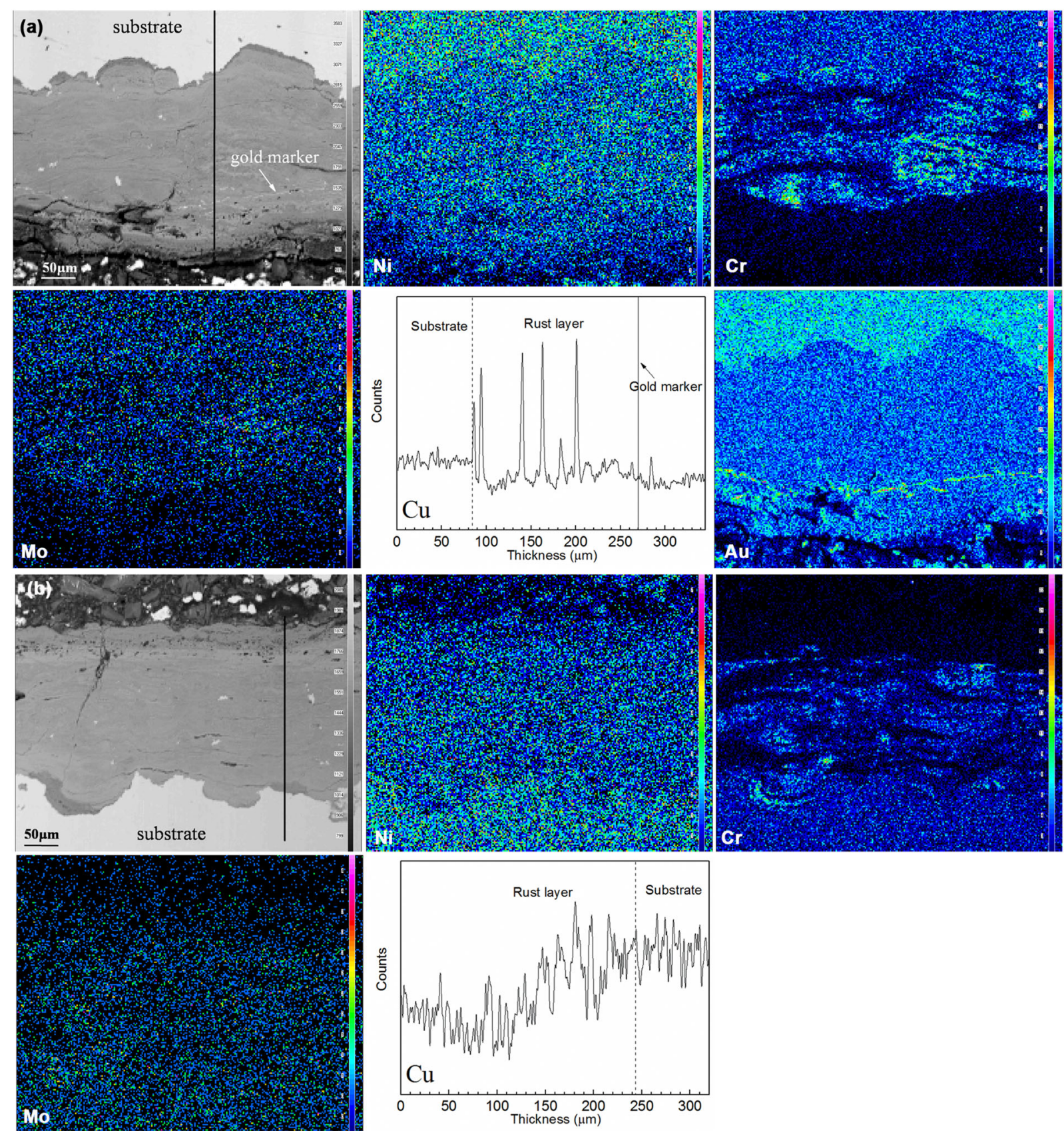

Fig. 10 Cross-sectional morphologies and element distribution (line scanning of $\mathrm{Cu}$ element and area scanning of other elements) in the rust layers with gold markers a, without gold markers b formed on the weathering steel corrupted for $240 \mathrm{~h}$

(such as $\gamma-\mathrm{FeOOH}$ and $\beta-\mathrm{FeOOH}$ ) in the rust layer formed on the weathering steel corrupted for $336 \mathrm{~h}$ decreases slightly compared with that of $144 \mathrm{~h}$ (as shown in Fig. 3), and hence the increase in compactness of the rust layer is a major factor inhibiting the cathodic and anodic reactions. Compared with the rusted carbon steel corrupted for $336 \mathrm{~h}$, the corrosion potential of the rusted weathering steel moves to the positive, and the anodic and cathodic processes are inhibited, which indicates that the protective property of the rust layer formed on the weathering steel is better than that on the carbon steel. Since the content of $\gamma-\mathrm{FeOOH}$ and $\beta-\mathrm{FeOOH}$ in the rust layer formed on the weathering steel is slightly lower than that on the carbon steel, the difference in the protective property of the rust layers is mainly due to variation in the compactness of the rust layer. 


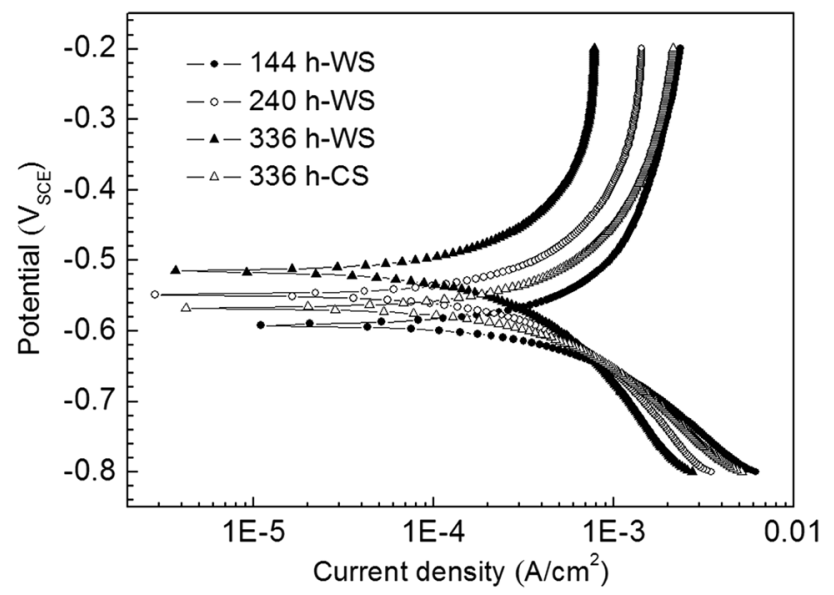

Fig. 11 Polarization curves of the rusted weathering steel (WS) and carbon steel (CS) without gold markers after different corrosion times

\section{Discussion}

The two new phenomena found in present work can be used to propose mechanisms of the structural evolution of the rust layers on the steel in the atmosphere. Firstly, the inner rust layer of the carbon steel is thicker than that of the weathering steel, while the rust layer of the weathering steel is more compact. This phenomenon indicates that the alloy elements affect the growth pattern of the rust layers, since the structure of the rust layer is closely related to its growth pattern. Secondly, in the environment containing chloride ions, $\gamma-\mathrm{FeOOH}$ is mainly located in the outer rust layer, while $\beta-\mathrm{FeOOH}$ is mainly located in the inner rust layer, and the distribution of the rust compounds in the rust layers is related to their formation mechanism.

\subsection{Influence of Alloy Elements on Growth Pattern of Rust Layer}

As described in the result's section, the alloy elements have a great effect on the evolution of the rust layer structure. Since $\mathrm{Cu}$ ions can accelerate air oxidation of iron (II), generating $\mathrm{Fe}(\mathrm{OH})_{3}$, and then precipitation of $\mathrm{Fe}(\mathrm{OH})_{3}$ attached to the surface of defects in the rust layer due to its low solubility [5], $\mathrm{Cu}$ element can improve the compactness of the rust layer. Meanwhile, $\mathrm{Cu}$ inhibits the growth and crystal structure development of the rust particles, improving the stability of the rust layer [28, 29]. Ni can substitute for $\mathrm{Fe}$ ions in the oxide, forming a spinel oxide, which also improves the stability of the rust layer [24], and hence the distribution of $\mathrm{Ni}$ in the rust layer inhibits the dissolution of the rust compounds in the aquatic solution. $\mathrm{Cr}$ and Mo elements can not only improve the stability of the rust layers, but also change the structure of the rust layer, so that it possesses cation selectivity, which effectively prevents the $\mathrm{Cl}$ ions from moving in the inner rust layer [30-33]. The rust layer with cation selectivity will inhibit the internal development of the rust layer, since it is difficult for the $\mathrm{Cl}$ ions to enter the channel with cation selectivity to neutralize the positive charge of $\mathrm{Fe}^{2+}$ ions generated by corrosion [5]. Based on the above analysis, $\mathrm{Ni}, \mathrm{Cr}$, Mo and $\mathrm{Cu}$ elements inhibit the dissolution of the rust compounds and promote the precipitation of the corrosion products, which restrain the formation of defects and accelerate the repair of the defects.

Moreover, the internal development of the rust layer and the Pilling-Bedworth ratio [39] of the internal rust layer of around 2 (according to the data in Fig. 1a, 7) suggest the presence of compressive stress in the internal rust layer, and the accumulative compressive stress can lead to fracture and induce the formation of cracks in the internal rust layer. Since the external rust layer has a porous nature, the defects of the inner rust layer play a significant role in the corrosion resistance of the steel in the aqueous solution. If the compactness of the rust layer increases, the accumulative compressive stress in the internal rust layer decreases since the internal development of the rust layer is restrained, and hence probability of crack formation will be reduced. The formation of the defects in the internal rust layer reduces the compactness of the rust layer, while corrosion products attached to the surface of the defects lead to an increase in the compactness of rust layer. So the more compact rust layer with cation selectivity formed on the weathering steel inhibits the internal development of the rust layer, which reduces the probability of crack formation in the inner rust layer. Based on the above analysis, $\mathrm{Ni}, \mathrm{Cr}$, Mo and $\mathrm{Cu}$ elements restrain the formation of the defects, which promote the compactness of the rust layers.

\subsection{Influence of Rust Growth Pattern on its Structure}

According to the morphologies and Raman spectroscopy analysis of the rust layers, the outer rust layers with a porous nature are mainly composed of $\alpha-\mathrm{FeOOH}, \gamma$ $\mathrm{FeOOH}$ and $\mathrm{Fe}_{3} \mathrm{O}_{4}$, while the inner rust layers with a fine and compact nature are mainly composed of $\alpha-\mathrm{FeOOH}, \beta$ $\mathrm{FeOOH}$ and $\mathrm{Fe}_{3} \mathrm{O}_{4}$, and the crystallinity of the inner rust layers is lower than that of the outer rust layers. The variation of the structure and distribution of the rust compounds in rust layers is closely related to the growth pattern of the rust layers.

The outer rust layer is formed by the corrosion products deposited on the surface of the rust layer and is influenced by the dissolution and precipitation of the rust compounds [5], and this dissolution/precipitation mechanism could explain the porous nature of the outer rust layer. The generation of $\gamma-\mathrm{FeOOH}$ is possible under the condition of 
sharp changes in the redox potential [40]. Since the oxygen concentration of the aquatic solution changes significantly on the surface of the outer rust layer during the drying stage, it benefits to the formation of $\gamma$-FeOOH. The $\gamma$ $\mathrm{FeOOH}$ is generated by oxidation of iron oxide or hydroxide. Dunnwald and Otto [37] verified that it is difficult for $\mathrm{Fe}_{3} \mathrm{O}_{4}$ to generate iron oxyhydroxide at room temperature. Stratmann [13] used the Kelvin vibration capacitance method to measure the variation in corrosion potential in the alternate wet/dry process. They found that it was difficult for $\mathrm{Fe}_{3} \mathrm{O}_{4}$ to generate iron oxyhydroxide, and proposed that $\gamma$ - $\mathrm{FeOOH}$ was generated by oxidizing the $\mathrm{Fe}(\mathrm{OH})_{2}$. As described above, $\gamma$-FeOOH should be generated by oxidizing the precipitation of $\mathrm{Fe}(\mathrm{OH})_{2}$ attached to the outer rust layer surface as shown in Eq. (5). The $\mathrm{Fe}_{3} \mathrm{O}_{4}$ is generated by reduction of active rust compounds (such as $\gamma-\mathrm{FeOOH}$ ) [12] as shown in Eq. (6), while $\alpha-\mathrm{FeOOH}$ is generated by the dehydration of $\mathrm{Fe}(\mathrm{OH})_{3}$ or the oxidation of $\mathrm{Fe}(\mathrm{OH})_{2}$ [38] as shown in Eqs. (5) and (7).

$4 \mathrm{Fe}(\mathrm{OH})_{2}+\mathrm{O}_{2} \rightarrow 4 \mathrm{FeOOH}+2 \mathrm{H}_{2} \mathrm{O}$,

$3 \mathrm{FeOOH}+\mathrm{e}+\mathrm{H}^{+} \rightarrow \mathrm{Fe}_{3} \mathrm{O}_{4}+2 \mathrm{H}_{2} \mathrm{O}$,

$\mathrm{Fe}(\mathrm{OH})_{3} \rightarrow \mathrm{FeOOH}+\mathrm{H}_{2} \mathrm{O}$.

Since the smaller area of the internal rust layer contacts with electrolyte solution, the fewer active rust compounds undergo the dissolution/precipitation reaction, which leads to the formation of a more compact rust layer with a low crystalline. As chloride ions are usually enriched in the anodic area, and $\beta-\mathrm{FeOOH}$ is a tubular crystal structure which requires some elements (such as $\mathrm{Cl}$ and $\mathrm{F}$ ) to stabilize the presence of this structure, $\beta-\mathrm{FeOOH}$ is only located in the inner rust layer. The generation mechanism of $\mathrm{Fe}_{3} \mathrm{O}_{4}$ and $\alpha-\mathrm{FeOOH}$ is similar to that of the outer rust layer.

\section{Conclusions}

1. The corrosion kinetics of the steels is closely related to the structure of the rust layers. The rust layer formed on the weathering steel becomes more compact as the corrosion proceeds, and it is more compact than that on carbon steel.

2. $\mathrm{Cr}, \mathrm{Mo}$ and $\mathrm{Cu}$ are enriched in the inner rust layer, while Ni uniformly distributed in the whole rust layer. The elements contained in the weathering steel suppress rust crystallization and impede the rust layer growth to an internal development, which is beneficial for the formation of a protective rust layer.

3. $\gamma-\mathrm{FeOOH}$ is mainly located in the outer rust layer, while $\beta-\mathrm{FeOOH}$ is mainly located in the inner rust layer, and the distribution of the rust compounds in the rust layer is closely related to the growth pattern of the rust layer. Furthermore, the structural difference between the inner and outer rust layers is also related to the rust growth pattern.

Acknowledgments This work was financially supported by the National Natural Science Foundation of China (Grant Nos. 51304040 and 51275446) and Hebei Province Natural Science Foundation (No. E2016203395) and Young Teachers Independent Research Program of Yanshan University (No. 14LGB002) and Open Research Program of National Engineering Research Center for Equipment and Technology of Cold Strip Rolling (No. NECSR-201503).

\section{References}

[1] D.D.L. Fuente, I. Diaz, J. Simancas, B. Chico, M. Morcillo, Corros. Sci. 53, 604 (2011)

[2] K.E. Garcia, C.A. Barrero, A.L. Morales, J.M. Greneche, Corros. Sci. 50, 763 (2008)

[3] C. Thee, L. Hao, J.H. Dong, X. Mu, W. Ke, Acta Metall. Sin. (Engl. Lett.) 28, 261 (2015)

[4] F.R. Pérez, C.A. Barrero, K.E. García, Corros. Sci. 52, 2582 (2010)

[5] H. Tamura, Corros. Sci. 50, 1872 (2008)

[6] J.G. Castaño, C.A. Botero, A.H. Restrepo, E.A. Agudelo, E. Correa, F. Echeverria, Corros. Sci. 52, 216 (2010)

[7] Y.T. Ma, Y. Li, F.H. Wang, Corros. Sci. 51, 997 (2009)

[8] X.L. Gao, G.Q. Fu, M.Y. Zhu, Acta Metall. Sin. (Engl. Lett.) 25, $295(2012)$

[9] J. Guo, S.W. Yang, C.J. Shang, Y. Wang, X.L. He, Corros. Sci. 51, 242 (2008)

[10] T. Kamimura, S. Hara, H. Miyuki, M. Yamashita, H. Uchida, Corros. Sci. 48, 2799 (2006)

[11] S. Hara, T. Kamimura, H. Miyuki, M. Yamashita, Corros. Sci. 49, 1131 (2007)

[12] U.R. Evans, C.A.J. Taylor, Corros. Sci. 12, 227 (1972)

[13] M. Stratmann, Corros. Sci. 30, 715 (1990)

[14] N.W. Dai, J.X. Zhang, Q.M. Chen, X. Zhang, F.H. Cao, J.Q. Zhang, Acta Metall. Sin. (Engl. Lett.) 29, 373 (2016)

[15] V. Lair, H. Antony, L. Legrand, A. Chausse, Corros. Sci. 48, 2050 (2006)

[16] Q. Guo, J.H. Liu, M. Yu, S.M. Li, Acta Metall. Sin. (Engl. Lett.) 28, 139 (2015)

[17] H. Cano, D. Neff, M. Morcillo, P. Dillmann, I. Diaz, D. Fuente, Corros. Sci. 87, 438 (2014)

[18] M. Yamashita, H. Miyuki, Y. Matsuda, H. Nagano, T. Misawa, Corros. Sci. 36, 283 (1994)

[19] J.H. Dong, Corros. Sci. Prot. Technol. 22, 261 (2010)

[20] L. Hao, S.X. Zhang, J.H. Dong, W. Ke, Corros. Sci. 59, 270 (2012)

[21] Y.T. Ma, Y. Li, F.H. Wang, Mater. Chem. Phys. 112, 844 (2008)

[22] J. Monnier, D. Neff, S. Réguer, P. Dillmann, L. Bellot-Gurlet, Corros. Sci. 52, 695 (2010)

[23] X. Zhang, S.W. Yang, W.H. Zhang, H. Guo, X.L. He, Corros. Sci. 82, 165 (2014)

[24] T. Nishimura, T. Kodama, Corros. Sci. 45, 1073 (2003)

[25] I. Diaz, H. Cano, D. de la Fuente, B. Chico, J.M. Vega, M. Morcillo, Corros. Sci. 76, 348 (2013)

[26] M. Itou, A. Usami, K. Tanabe, H. Kihira, S. Ito, Nippon Steel Technol. Rep. 81, 79 (2000)

[27] M. Kimura, H. Kihira, M. Hashimoto, M. Hashimoto, T. Senuma, Corros. Sci. 47, 2499 (2005) 
[28] K. Inouye, K. Ichimura, K. Kaneko, T. Ishikawa, Corros. Sci. 16, 507 (1976)

[29] T. Ishikawa, M. Kumagai, A. Yasukawa, K. Kandori, T. Nakayama, Corros. Sci. 44, 1079 (2002)

[30] Q.C. Zhang, J.S. Wu, J.J. Wang, W.L. Zheng, J.G. Chen, Mater. Chem. Phys. 77, 603 (2002)

[31] Y.H. Qian, C.H. Ma, D. Niu, J.J. Xu, M.S. Li, Corros. Sci. 74, 424 (2013)

[32] M. Sakashita, N. Sato, Corros. Sci. 17, 473 (1977)

[33] L. Hao, S.X. Zhang, J.H. Dong, W. Ke, Corros. Sci. 54, 244 (2012)
[34] Y.Y. Chen, H.J. Tzeng, L.I. Wei, L.H. Wang, J.C. Oung, Corros. Sci. 47, 1001 (2005)

[35] E. Burger, M. Fénart, S. Perrin, D. Neff, P. Dillmann, Corros. Sci. 53, 2122 (2011)

[36] S.T. Wang, S.W. Yang, K.W. Gao, X.A. Shen, X.L. He, Acta Metall. Sin. 44, 1116 (2008). (in Chinese)

[37] J. Dunnwald, A. Otto, Corros. Sci. 29, 1167 (1989)

[38] J.J. Morgan, W. Stumm, Aquatic Chemistry, 3rd edn. (Wiley, New York, 1996), pp. 274, 326-362

[39] N.B. Pilling, R.E. Bedworth, J. Inst. Met. 29, 529 (1923)

[40] A.O. Alelseev, T.V. Alelseev, Eur. Soil Sci. 33, 1053 (2000) 